\title{
Discrete Element Numerical Simulation Based on Rebound Modulus of Weathered Phyllite Fillers
}

\author{
WANG Yueyue ${ }^{1, a,{ }^{*}}$, MAO Xuesong ${ }^{1, b}$, NIE Menglan ${ }^{1, c}$ \\ ${ }^{1}$ School of Chang An University, Shanxi 710064, China. \\ a, ${ }^{\star}$ 359004808@qq.com \\ b xuesongxian@aliyun.com \\ c413197819@qq.com
}

Keywords: Weathered phyllite fillers; PFC2D; Laboratory experiments; Microscopic properties

\begin{abstract}
In order to research the microscopic variations of weathered phyllite fillers in the bearing plate experiment, the spheroids of intergranular interaction model and the particle flow theory of discrete element method were adopted to simulate soil particles in this paper. Calculation model of weathered phyllite with 55\% rock content was established by $\mathrm{PFC}^{2 \mathrm{D}}$. And the microscopic parameters of the granular unit were further revised on the basis of laboratory experiments. Besides, the stress-strain relationship and the microscopic properties between particles were studied under loading and unloading conditions both by numerical simulation and laboratory test. Results show that the resilient modulus and peak strength of weathered phyllite fillers were closely related to the microscopic parameters in the numerical model. Furthermore, the numerical simulation results coordinated well with the test results. The research results in this paper could provide references for further exploration of the properties of weathered phyllite fillers.
\end{abstract}

\section{Introduction}

As the foundation of pavement structure, the size of the subgrade strength depends on its ability to resist deformation and destruction. Common road engineering earth-based resilience modulus test can be broadly divided into two categories, one is the indoor test, one is the field test. Using the small-plate indoor method, the $p$ - 1 curve with different particle sizes, moisture contents and the modulus of elasticity can be obtained ${ }^{[1]}$. However, it is impossible to intuitively know the law of the development of the modulus of elasticity and the microscopic changes of the filler during the loading and unloading of the small-sized bearing plate test. In addition, the indoor test is not only heavy and time-consuming operation, engineering large, and experimental data vulnerable to external factors.

However, engineering soft rock can be used as a roadbed filler filling subgrade in the specification there is no clear rule, and internal displacement of the sample particles and the rules of stress variation can't be macroscopically measured. Discrete element is a suitable method to simulate the numerical value of the bulk material and has achieved remarkable results since Cundall

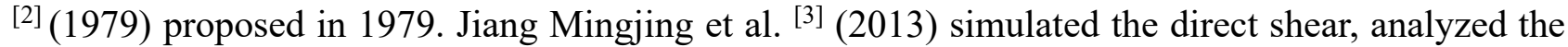
microscopic motion of the particle swarm and corrected the influence of the inner friction of the shear wall on the shear strength. Cheng et al. ${ }^{[4]}$ (2003) used PFC to perform triaxial stress-strain simulation on the rock mass clumps, and obtained the relation curves of stress, strain, displacement and peak intensity. Zhou Jian et al. ${ }^{[5]}$ (2000) applied the particle flow theory to simulate the stress-strain curve of the plane strain test of sand and clay.

However, phytoliths are expensive and time-consuming in field tests and in-house tests, and experimental data are susceptible to external factors, numerical simulation of particle flow theory can break through the limitations of conventional geotechnical tests in terms of equipment capabilities and test conditions, which can make some predictions on the theoretical constitutive behavior of actual soil samples. Therefore, the method of numerical simulation as a supplement to the test, while revealing the microscopic mechanical properties is very necessary. 


\section{Small loading plate test}

It can be seen from the results of small indoor load plate tests ${ }^{[6]}$, the basic physical parameters of the sample were as follows: the coefficient of curvature $\mathrm{Cc}$ was 1.38 , the coefficient of non-uniformity $\mathrm{Cu}$ was 24.63 , the maximum dry density was $2.358 \mathrm{~g} / \mathrm{cm}^{3}$, the water content was $5 \%$, the particle size ranges from $0.075 \mathrm{~mm}$ to $53 \mathrm{~mm}$. The gradation combined particle composition of the phyllite fillers with the stone content of $55 \%$ can be obtained by conversion, as shown in the following Table 1 . The data measured in the experiment were processed to draw a $p-1$ curve with water content of 5\% and stone content of 55\%, as shown in Fig. 1.

Table 1. Particle Size Combinations of Phyllite Fillers with 55\% Stone Content $\quad(\mathrm{Kg})$

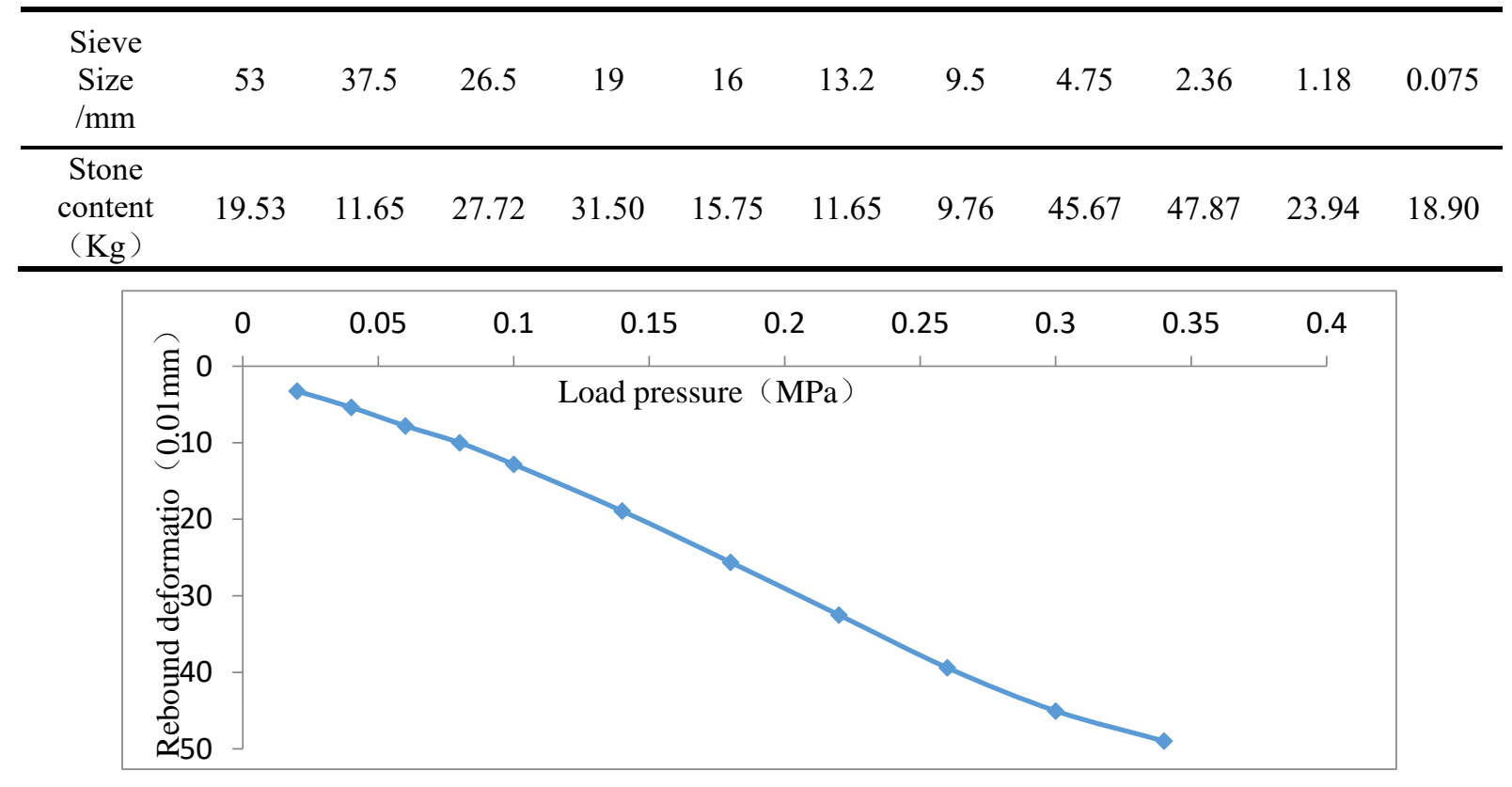

Fig. 1. the $P$ - $l$ curve with $55 \%$ rock content

\section{Particle flow numerical simulation of $55 \%$ stone containing phyllite particles}

\subsection{Model establishment}

Combined with the above-mentioned indoor small-scale load-bearing test, the $\mathrm{PFC}^{2 \mathrm{D}}$ simulation rectangular model size was width $\times$ height $=600 \mathrm{~mm} \times 550 \mathrm{~mm}$. Note that the wall to be longer, or it may be the phenomenon of particle overflow. In order to ensure the formation and efficiency of the particles, first generated small diameter particles, and then restored the radius, finally through the cycle to eliminate non-uniform stress within the sample. The maximum diameter of the ball was $53 \mathrm{~mm}$, the minimum diameter was $0.075 \mathrm{~mm}$, the resulting number of particles was around 7000 . Set the particle density, friction coefficient, normal stiffness, tangential stiffness, normal bond strength, tangential bond strength, and particle diameter range of mass ratio [7]. The two-dimensional image of the biaxial calculation model was shown in Fig. 2. 


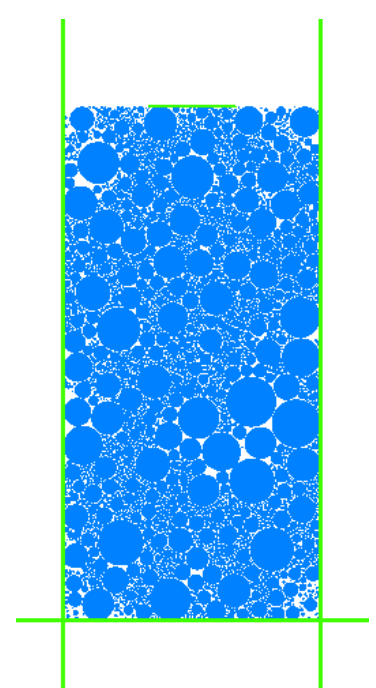

Fig. 2. Calculation model

\subsection{Boundary conditions}

Specific boundary conditions formula can refer to the literature ${ }^{[8]}$.

During the loading process, the boundary conditions are controlled by the servo mechanism, using the following equation:

$$
\left|\frac{\sigma^{(t)}-\sigma^{(w)}}{\sigma^{(t)}}\right| \leq \varepsilon
$$

Where: $\sigma^{(t)}$ is the stress of the model; $\Delta \sigma^{(w)}$ is the wall average stress increment ; $\varepsilon$ is an infinite decimal.

\subsection{Determination of mesoscopic parameters}

After a large number of trial calculations and repeated adjustment of the fine-grain particles parameters, when the numerical test results were close to those of the indoor test, the model can be considered to simulate this material and can be further studied. Selected mesoscopic parameters of the $\mathrm{PFC}^{2 \mathrm{D}}$ numerical model which corresponding to the macroscopic mechanical properties of the simulated material as shown in Table 2.

Table 2. Meso-mechanics Parameters of $\mathrm{PFC}^{2 \mathrm{D}}$ Numerical Simulation

\begin{tabular}{ccccc}
\hline $\begin{array}{c}\text { Wall stiffness } \\
(\mathrm{N} / \mathrm{m})\end{array}$ & Porosity & Friction factor & $\begin{array}{c}\text { tangential } \\
\text { stiffness }(\mathrm{N} / \mathrm{m})\end{array}$ & $\begin{array}{c}\text { Particle normal } \\
\text { stiffness }(\mathrm{N} / \mathrm{m})\end{array}$ \\
\hline $1 \times 10^{9}$ & 0.103 & 0.7 & $5.5 \times 10^{8}$ & $1.1 \times 10^{7}$
\end{tabular}

Here didn't consider the friction between model wall and particle, so the friction coefficient between wall and granules was zero.

\subsection{Calculation process}

During the test, loading and unloading tests were performed on the way of strain control by specifying the top and bottom restraint speeds. In each phase of the test, the constraints on the left and right sides were automatically controlled by a numerical servo mechanism (performed by the FISH function), so that the confining pressure remained constant throughout the test. The axial strain of the specimen was the ratio of the relative displacement of the two plates to the initial sample height, and the size of the stress was the force acting on the board divided by the area of the board. 


\section{Analysis of simulation results}

\subsection{Comparison of rebound modulus}

Through the encoding process, version 5.0 of PFC2D can be directly obtained rebound modulus parameter values. When the moisture content was $5 \%$ and the particle size distribution was 55\%, the modulus of elasticity was $39.71 \mathrm{MPa}$. The rebound modulus of the small load-bearing plate test was $39.13 \mathrm{MPa}$, which were very close. Therefore, PFC can obtain the macroscopic test results well through simulation and intuition, and reduce human experimental error and calculation error, and PFC had a good guiding significance.

\subsection{Simulation analysis of stress - strain curves}

The experimental simulation curve for a 55\% stone containing particle fraction was shown in Fig.3 Comparing Fig. 1 can be seen that the simulation showed a good change of stress and strain under the $55 \%$ stone-containing particle size distribution with obvious plastic deformation. As the sample reached its peak strength, the particles within the sample were rearranged and the internal stress distribution was not uniform, the stress-strain curve appeared to fluctuate.

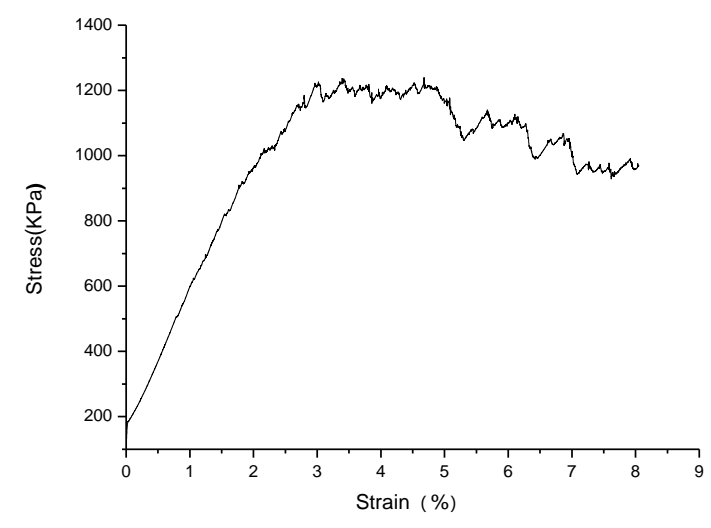

Fig.3. Stress-strain curve at 55\% stone content

\subsection{Variation analysis of particle displacement and contact force distribution}

$\mathrm{PFC}^{2 \mathrm{D}}$ believed that the macroscopic deformation of soil was due to the change of the position between the grains, instead of the soil particle deformation ${ }^{[8]}$. Fig. 4 was the particle displacement field changes, which under the action of axial pressure. At the beginning of the pressurization phase, as the axial stress increased, the particles approached each other, increased the number of contact points and the contact area, granules from both ends to the middle of the pressure, and the middle part of the particles appear squeezed phenomenon. Displacement of particles showed the upper and lower ends sharply moved to the middle, but the movement of the central particles was not obvious (As shown in Fig.4 (a)); In the unloading phase, when the sample reached the peak strength, stress concentration gradually subsided, the whole sample showed axial shrinkage and radial expansion of the deformation characteristics, so the displacement of the particles moved from the inside to the outside as a whole (As shown in Fig.4 (b)). Fig.4 (c) was a color legend of particle size. Fig.5 showed the contact force distribution of the particles during the pressurized and unloading process, and it can be seen that the particles in the entire sample were extruded to form a dense network of contact stresses, indicating that all the particles were internally adjusted (As shown in Fig.5 (a)); In the unloading phase, the contact stress appeared as a relatively axial distribution (As shown in Fig.5 (b)). 


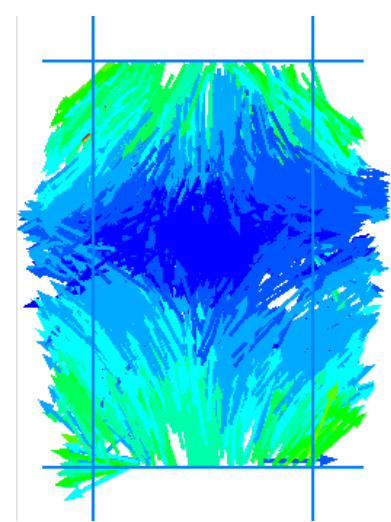

(a) Pressurization phase

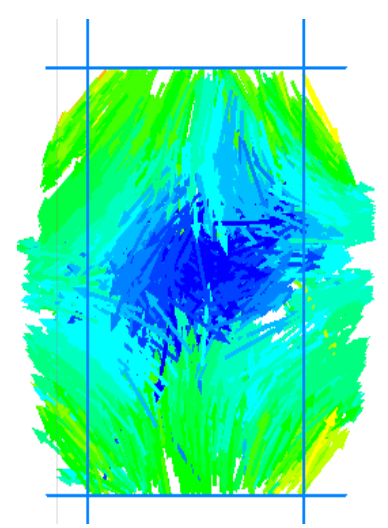

(b) Unloading stage

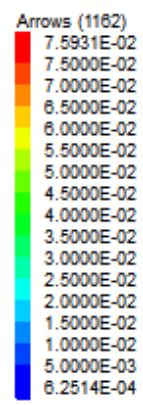

(c) Color illustration

Fig.4. Displacement field distribution

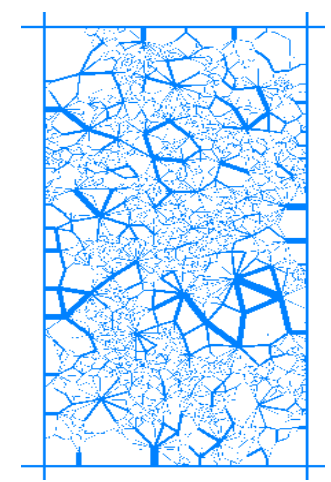

(a) Pressurization phase

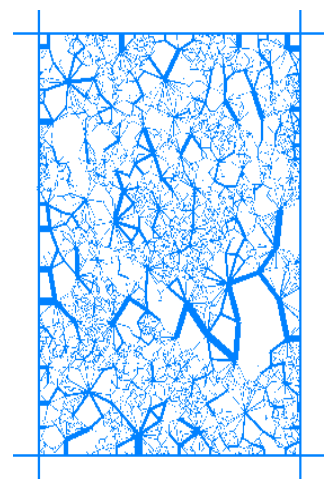

(b) Unloading stage

Fig.5. Distribution of contact force between particles

\section{Conclusions}

(1) From the results of the small-scale indoor test on the weathered phyllite fillers with $55 \%$ stone content, the $p-1$ curve obtained from the test was smooth and met the general requirements. According to the $p$ - $l$ curve to calculate the modulus of elasticity, it's found that the rebound modulus met the requirements of the design code, and the rebound modulus of soil foundation should be greater than $30 \mathrm{MPa}$.

(2) The $p$ - $l$ curve obtained from the indoor experiment was compared with the stress-strain curve obtained through numerical simulation. Comparing the indoor experiment and numerical simulation, the $p$ - $l$ curve and the stress- strain curve were fitting well, and both of the rebound modulus values were also very close. This showed that the mesoscopic parameters set by this simulation were in good agreement with the properties, grading and loading methods of the indoor test packing. This simulation can also well verify the accuracy of indoor small load plate test results. It also provided favorable technical support for the next exploration of other microscopic properties and mesoscopic changes of weathered phyllite fillers by using $\mathrm{PFC}^{3 \mathrm{D}}$ software.

(3) Comparing the results of indoor experiment and numerical simulation, it's found that the variation law of the displacement field in each stage of pressurization and unloading was consistent with the macroscopic phenomenon of the indoor bearing plate test, and the stress-strain curve also accords with the law. The simulation not only better reflected the movement and the contact force distribution characteristics of the phyllite meso-particles, but also the validity of particle flow numerical simulation was verified well.

As a preliminary study, this paper proved that $\mathrm{PFC}^{2 \mathrm{D}}$ can directly simulate the macroscopic test of weathered phyllite fillers, which can provide the foundation for other experimental simulations of weathered phyllite. Many aspects such as different mesoscopic parameters, particle size distribution, porosity and so on needed study in the near future. 


\section{Acknowledgement}

This work was financially supported by National Science and Science Technology fund. The project name is Study on Hydro-mechanical Coupling and Long-term Deformation Characteristics of Subgrade Filled with Strongly Weathered Thousand Rocks (Grant NO.211021130246).

This work was supported by the Special Found for Basic Scientific Research of Central College of Chang'an University (300102218408). The authors gratefully acknowledged their financial supp ort.

\section{References}

[1] Li Wenling (2016). Study on the rebound modulus demodulation of weathered phyllite subgrade fillers [D]. Chang'an University.

[2] Cundall PA, Strack ODL. (1979). A discrete numerical model for granular assemblies. Geotechnique, 29(1):47-65.

[3] Jiang Mingjing, Chen He, Liu Fang (2013). Rock microcosmic cementing model and numerical simulation of discrete element method [J]. Chinese Journal Rock Mechanics and Engineering, 32(1):6.

[4] CHENG Y P, NAKATA Y, BOLTON MD (2003). Discrete element simulation of crushable soil [J]. Geotechnique,53(7): 633-641.

[5] Zhou Jian, Chi Yuwei, Chi Yong (2000). Particle flow simulation of sand and biaxial test [J]. Chinese Journal of Geotechnical Engineer-ing, 22 (6) : 701 704.

[6] Li Wenlin. Study on Attenuation Characteristics of Resilient Modulus of Weathered Ruby Rock Subgrade Filler [D]. Chang'an University,2017.

[7] Wu Qian (2015). Study on the effect of soft clay bound water on secondary consolidation and long - term intensity and it's Mechanism [D]. Jilin University.

[8] Li Shibo, Wang Changming, Ma Jianquan (2013). Study on the three - axis shear process microcosmic changes of Longxi loess [J]. Rock and Soil Mechanics, 34(11):3299-3305. 